\title{
Oxidative stress of crystalline lens in rat menopausal model
}

\section{O estresse oxidativo do cristalino em modelo de rata na menopausa}

Semra Acer ${ }^{1}$, Gökhan Pekel ${ }^{1}$, Vural Küçükatay ${ }^{2}$, Aysun Karabulut ${ }^{3}$, Ramazan YaĞcl ${ }^{1}$, Ebru Nevin Çetin ${ }^{1}$, Şahika Pinar Akyer ${ }^{4}$, Barbaros Şahin ${ }^{5}$

\section{ABSTRACT}

Purpose: To evaluate lenticular oxidative stress in rat menopausal models.

Methods: Forty Wistar female albino rats were included in this study. A total of thirty rats underwent oophorectomy to generate a menopausal model. Ten rats that did not undergo oophorectomy formed the control group (Group 1). From the rats that underwent oophorectomy, 10 formed the menopause control group (Group 2), 10 were administered a daily injection of methylprednisolone until the end of the study (Group 3), and the remaining 10 rats were administered intraperitoneal streptozocin to induce diabetes mellitus (Group 4). Total oxidant status (TOS), total antioxidant capacity (TAC), and oxidative stress index (OSI) measurements of the crystalline lenses were analyzed.

Results: The mean OSI was the lowest in group 1 and highest in group 4. Nevertheless, the difference between the groups was not statistically significant in terms of OSI ( $p>0.05)$. The mean TOS values were similar between the groups ( $p>0.05$ ), whereas the mean TAC of group 1 was significantly higher than that of the other groups $(p<0.001)$

Conclusions: Our results indicate that menopause may not promote cataract formation.

Keywords: Menopause; Cataract; Oxidative stress; Lens, crystalline

\section{RESUMO}

Objetivo: Avaliar o estresse oxidativo lenticular em modelos de ratas na menopausa. Métodos: Quarenta ratos albinos femininos tipo Wistar foram incluídos neste estudo. Trinta ratas foram submetidas à ooforectomia para gerar o modelo de menopausa e 10 ratas formaram o grupo controle (Grupo 1). Dentre as ratas ooforectomizadas, 10 formaram o grupo controle menopausa (Grupo 2), 10 ratas receberam injeção diária de metilprednisolona até ao final do estudo (Grupo 3) e 10 ratas receberam estreptozotocina por via intraperitoneal para induzir diabetes mellitus (Grupo 4). O estado oxidante total (TOS), a capacidade total antioxidante (TAC) e as medições do indice de estresse oxidativo (OSI) dos cristalinos foram analisados.

Resultados: A média de OSI foi menor no grupo 1 e maior no grupo 4. Todavia, a diferença entre os grupos não foi estatisticamente significativa ( $>>0,05)$. Os valores médios TOS foram semelhantes entre os grupos ( $p>0,05)$, enquanto a média de TAC grupo 1 foi mais elevada do que nos outros grupos ( $p<0,001)$.

Conclusões: Nossos resultados indicam que a menopausa podem não promover a formação de catarata.

Descritores: Menopausa; Catarata; Estress oxidativo; Cristalino

\section{INTRODUCTION}

Cataract is the most common cause of treatable blindness worldwide. Therefore, research related to the etiologic factors of cataractogenesis is always popular. Some well-known systemic conditions such as diabetes mellitus (DM) and systemic steroid intake promote cataract formation ${ }^{(1-4)}$. Although it is controversial, some reports have shown the protective effect of estrogen against cataractogenesis(5,6). Therefore, the decrease in estrogen level with the onset of menopause may increase the risk of cataract in women ${ }^{(5,6)}$.

Oxidative damage is a major cause of cataract formation ${ }^{(7)}$. Accumulation of oxidized lens components and decreased capacity of repair mechanisms promote cataractogenesis in several conditions such as aging and $\mathrm{DM}^{(8,9)}$. In oxidative stress analysis, both the oxidant status and antioxidant capacity are important. Therefore, we used a practical, reliable, and effective method of oxidative stress analysis that measures total oxidant status (TOS) and total antioxidant capacity (TAC) in the lens ${ }^{(10,11)}$.

We hypothesized that lenticular oxidative stress analysis may provide objective data on the cataractogenic effect of some systemic conditions. In this study, we aimed to compare the severity of len- ticular oxidative stress generated by diabetes, systemic steroid use, and menopause in animal models. To the best of our knowledge, this study is the first in the literature to study the effects of systemic conditions on cataractogenesis using rat models.

\section{METHODS}

Forty mature (4-month-old) Wistar female albino rats with an average weight of $250 \mathrm{~g}$ were used in this study. The study adhered to the tenets of the Association for Research in Vision and Ophthalmology statement for the use of animals in research. The study protocol was approved by the Animal Care and Use Committee of Pamukkale University, Turkey.

\section{Study GROUPS}

The rats were obtained from the Experimental Research Unit of our university. The animals were housed in groups of four to five rats in stainless steel cages under standard conditions $\left(24 \pm 2^{\circ} \mathrm{C}\right.$ and $50 \pm 5 \%$ humidity) with a 12-h light-dark cycle. The rats were fed ad libitum with standard rat chow and tap water. The experiments were performed between 9:00 and 12:00 AM.
Submitted for publication: November 16, 2015 Accepted for publication: March 16, 2016

Department of Ophthalmology, Pamukkale University, Denizli, Turkey.

2 Department of Physiology, Pamukkale University, Denizli, Turkey.

Department of Gynecology and Obstetrics, Pamukkale University, Denizli, Turkey.

4 Department of Anatomy, Pamukkale University, Denizli, Turkey.

${ }^{5}$ Experimental Animals Unit, Pamukkale University, Denizli, Turkey.
Funding: This study was supported by Pamukkale University Scientific Research Projects Committee (Project number: 2013BSP020).

Disclosure of potential conflicts of interest: None of the authors have any potential conflict of interest to disclose.

Corresponding author: Semra Acer. Pamukkale University Medical School. Ophthalmology Department. Kınıklı, Denizli, 20070 - Turkey - E-mail: semraacer2002@yahoo.com

Approved by the following research ethics committee: Pamukkale University (\#2013/005). 
Thirty rats underwent oophorectomy to induce menopausal status. Oophorectomy was performed under sterile conditions via a midline incision (Figure 1) after anesthetization using intraperitoneal injection of ketamine hydrochloride $(90 \mathrm{mg} / \mathrm{kg}$; Ketalar, Pfizer, Espoo, Finland) and xylazine (10 mg/kg; Kepro xylazine 201, Biopharm, Istanbul, Turkey). The incisions were closed with 3.0 polyglactin sutures. The remaining 10 rats formed the control group (Group 1). Ten of the 30 rats that underwent oophorectomy constituted the menopause control group (Group 2). Beginning 1 week after the operation, methylprednisolone $(1 \mathrm{mg} / \mathrm{kg}$ ) was injected daily until the end of the study to mimic steroid treatment for rheumatologic diseases in 10 rats (Group 3). Group 4 consisted of rats that received intraperitoneal administration of streptozocin (50 mg/ $\mathrm{kg}$ ) to induce DM 1 week after the oophorectomy. Blood glucose level was checked 3 days after streptozocin administration, and values $>250 \mathrm{mg} / \mathrm{dL}$ were considered as positive for DM.

Three rats in the menopause-diabetes group died during follow-up. All of the rats were deeply anesthetized with intraperitoneal ketamine $(90 \mathrm{mg} / \mathrm{kg})$ and xylazine $(10 \mathrm{mg} / \mathrm{kg})$ and sacrificed by cervical dislocation 11 weeks after the oophorectomy. The crystalline lenses were gently extracted through a large limbal corneal incision while protecting the whole lens structure. Both lenses of the right and left eyes were analyzed. The tissues were stored at $-80^{\circ} \mathrm{C}$ for subsequent analysis. The values of TOS, TAC, and oxidative stress index (OSI) were measured in the lenses of the four different animal models and then compared among the groups. The investigators who measured the values were blinded to the composition of the groups.

The lens samples were homogenized with cold lysis tamponade (1 M Tris, 1\% sodium dodecyl sulfate, protease inhibitor cocktail; $\mathrm{pH}$ 7.4; Complete; Roche Diagnostics, Basel, Switzerland), and the supernatants were obtained after centrifuging at $4^{\circ} \mathrm{C}$ and $15,000 \times g$ for $10 \mathrm{~min}$. The protein levels of the supernatants were determined with the Lowry method ${ }^{(12)}$.

\section{Measurements of lens TOS and TAC}

TOS of the lens was measured with an automated colorimetric measurement method that was improved by Erel ${ }^{(10)}$. In this method,

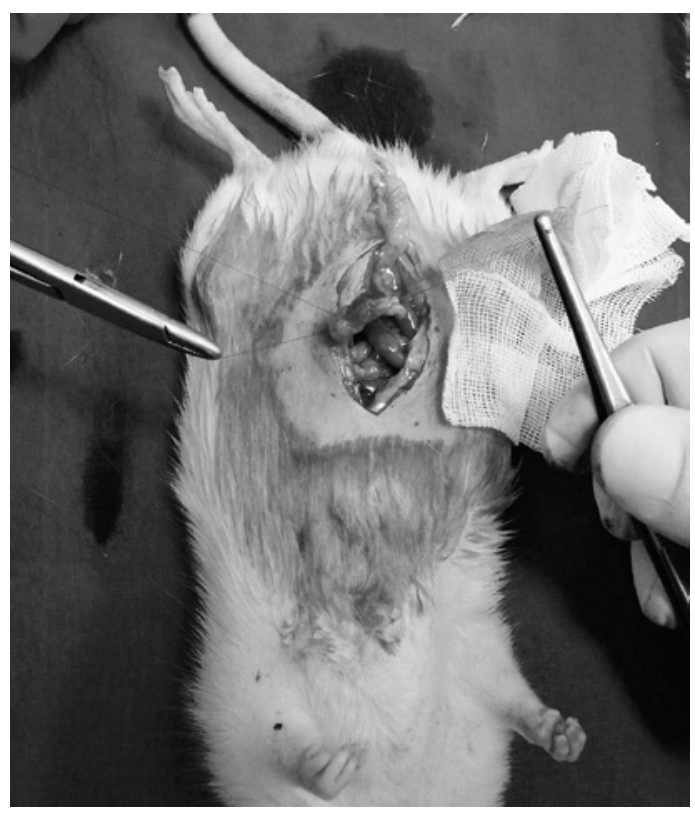

Figure 1. Procedure of oophorectomy to induce menopause in a rat model under general anesthesia. the ferrous ion-o-dianisidine complex is oxidized to ferric ion by the oxidants present in the sample. The glycerol molecules, which are plentiful in the reaction medium, intensify the oxidation reaction. The ferric ion forms a colored complex with xylenol orange in an acidic medium. The color intensity can be measured spectrophotometrically and is related to the total amount of oxidant molecules (lipids and proteins) present in the sample. The assay is calibrated using hydrogen peroxide, and the results are expressed in $\mu \mathrm{mol} / \mathrm{L}$.

TAC of the lens was measured with an automated colorimetric measurement method for TAC improved by Erel(11). In this method, the most powerful biological radical-the hydroxyl radical-is produced via the Fenton reaction, and it reacts with the colorless substrate o-dianisidine to produce the dianisyl radical, which has a bright yellowish brown color. After the addition of the lens homogenate, oxidative reactions are suppressed by the antioxidant components of the sample, thereby preventing color change and producing an effectual measure of the plasma TAC level. The assay results are indicated in $\mathrm{mmol} / \mathrm{L}$. The ratio of TOS to TAC is referred to as OSI. To perform this calculation, the result unit of measurement of TAC-mmol Trolox equivalent/L-was changed to $\mu \mathrm{mol}$ Trolox equivalent/L. OSI is calculated according to the following formula:

OSI (arbitrary unit) = TOS ( $\mu \mathrm{mol} / \mathrm{L}) /\left[\mathrm{TAC}(\mu \mathrm{mol} \text { Trolox equivalent/L)/100 }]^{(13)}\right.$

The lens morphology and cataract scores were assessed following the removal of the crystalline lenses. We used a basic cataract scoring system in which lenticular opacity is recorded as (+) and a clear lens is recorded as (-). We did not have the opportunity to take photographic images of the eyes. Gross examination and light microscopy were used to detect lenticular opacity.

\section{Statistical analysis}

All analyses were conducted using the computerized SPSS 21.0 program (Statistical Package for Social Sciences; IBM Corp., Armonk, NY, USA). $p$ values of $<0.05$ were considered statistically significant. The results are expressed as the means \pm standard deviation. Statistical analysis among the groups was performed using one-way analysis of variance followed by the least significant difference post hoc test. $p$ values from Levene's test were $>0.05$ for all studied parameters.

\section{RESULTS}

The mean TOS, TAC, and OSI values of the groups are summarized in table 1. The mean TOS was the highest in group 2 and lowest in group 3 as shown in figure $2 \mathrm{~A}$; however, the difference among the groups was not statistically significant ( $p=0.74)$. TAC was the highest in group 1 and lowest in group 3 as shown in figure $2 B$; the difference among the groups was statistically significant ( $p<0.001)$.

The mean OSI was the lowest in group 1 and highest in group 4 as shown in figure 2 C. OSI of group 4 was $60 \%$ higher than that of group 1, but the difference among the groups was not statistically significant $(p=0.56)$. We did not observe morphological differences in the crystalline lenses between the groups $(p>0.05)$, but lenticular opacity was more frequent in groups 3 and $4(p<0.05)$.

Table 1. The mean TOS, TAC, and OSI values of the four study groups are shown

\begin{tabular}{lccccc}
\hline & Group 1 & Group 2 & Group 3 & Group 4 & $\boldsymbol{p}$ \\
\hline TOS & $0.22 \pm 0.14$ & $0.23 \pm 0.16$ & $0.19 \pm 0.19$ & $0.22 \pm 0.15$ & 0.740 \\
TAC & $0.25 \pm 0.06$ & $0.17 \pm 0.05$ & $0.13 \pm 0.04$ & $0.15 \pm 0.03$ & $<0.001$ \\
OSI & $0.09 \pm 0.06$ & $0.13 \pm 0.07$ & $0.14 \pm 0.09$ & $0.15 \pm 0.09$ & 0.560 \\
\hline
\end{tabular}

( $\mathrm{TOS}=$ total oxidative status; $\mathrm{TAC}=$ total antioxidant capacity, $\mathrm{OSI}=$ oxidative stress index) Group 1=normal rats without oophorectomy (non-menopausal); Group 2=rats underwent oophorectomy only (menopause control); Group 3= rats underwent oophorectomy and received steroids; Group 4= rats underwent oophorectomy and had diabetes mellitus. 
A TOS

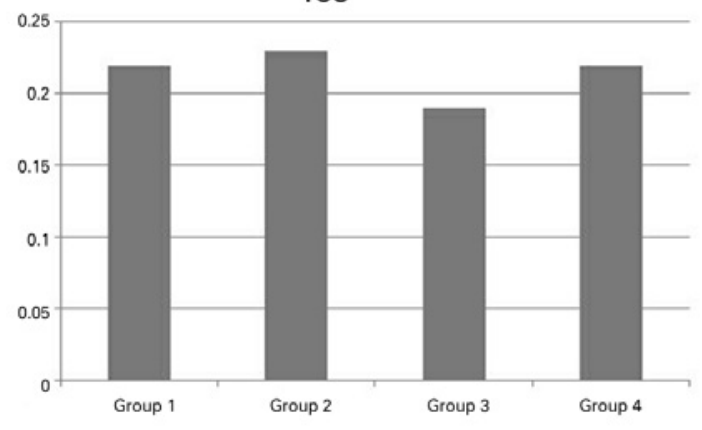

B
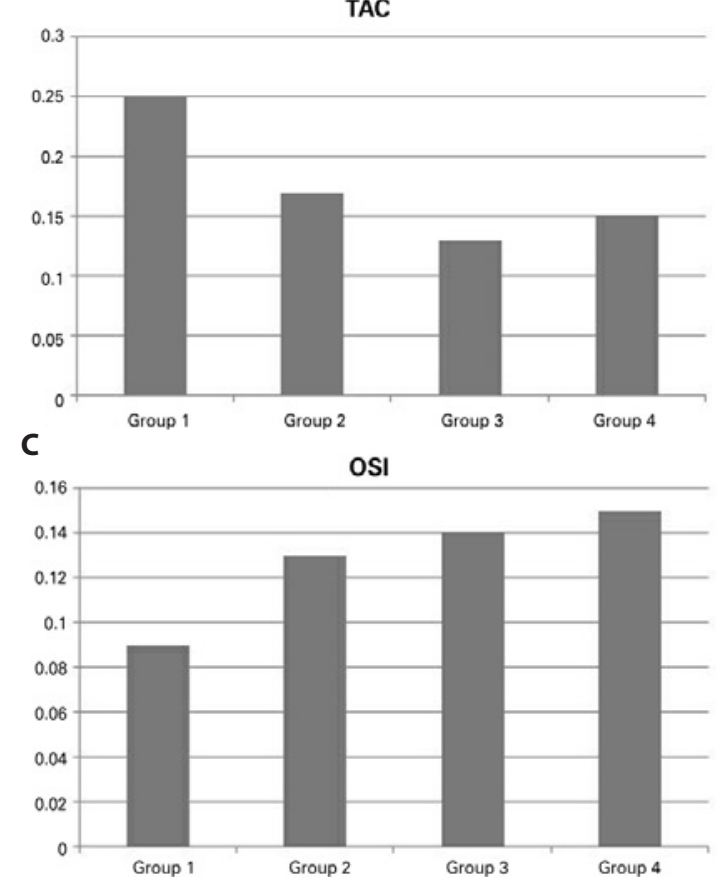

Figure 2. The mean total oxidant status (TOS) (2A), total antioxidant capacity (TAC) (2B), and oxidative stress index (OSI) (2C) values of the four groups are shown. Group 1:normal rats without oophorectomy (non-menopausal); Group 2: rats underwent oophorectomy only (menopause control); Group 3: rats underwent oophorectomy and received steroids; Group 4: rats underwent oophorectomy and had diabetes mellitus.

\section{DISCUSSION}

Our results showed that menopause may not be associated with cataract progression. The lenticular OSI in menopause-diabetes group is superior than that in menopause-steroid group. In general, oxidative stress is higher in males, and the higher level of estrogen in females protects them against aging ${ }^{(14)}$. Because cataract may be caused by the aging of the crystalline lens in most instances, it should be expected that the removal of estrogen increases lenticular OSI.

Several population-based studies have revealed that an increased rate of cataract surgery is associated with menopause ${ }^{(15,16)}$. Estrogen may exert a protective effect against the oxidative stress that is important in cataractogenesis ${ }^{(5)}$. In the present study, TOS increased and TAC decreased in the crystalline lens of rats following menopause induction. Nevertheless, our results suggested that estrogen removal does not promote cataract formation.

There is a strong association between cataract formation and systemic corticosteroid treatment ${ }^{(17)}$. Steroids may bind to lens proteins, resulting in the destabilization of the protein structure and the for- mation of cataract ${ }^{(18)}$. Systemic methylprednisolone administration has been shown to induce rat lens opacity ${ }^{(19)}$. The protective effect of methylprednisolone against oxidative injury has been found in several disease types ${ }^{(20-24)}$. However, no studies in the literature have related the impact of systemic methylprednisolone to the oxidative stress of crystalline lenses. In the present study, both TOS and TAC decreased in the lens of menopause-induced rats following systemic administration of methylprednisolone when compared with those of the controls. As OSI is the ratio of TOS to TAC, it is a better parameter for comparison than either TOS or TAC alone. Although OSI was found to be similar in the menopause only and menopause-steroid groups, lenticular opacity was more frequent in the menopause-steroid group.

DM increases oxidative stress in tissues, which in turn plays a role in the pathogenesis of various diabetic complications such as cataract $^{(25,26)}$. Reactive oxygen species promote a series of cellular responses that result in abnormal cellular functions. The polyol pathway was found to be an important contributor to oxidative stress in the lenses of diabetic mice ${ }^{(25)}$. Inhibition of aldose reductase, an important enzyme in the polyol pathway, was shown to be effective at preventing cataract formation ${ }^{(27)}$. In the present study, both TOS and TAC were lower in the menopause-diabetes group than in the menopause only group. However, OSI was the highest in the menopause-diabetes group, which could be interpreted as the most cataractogenically influenced.

Lenticular oxidative stress accumulation such as that seen in menopause does not necessarily mean cataract formation. It is important to find the association between OSI and lens opacity. Although our study lacks detailed lens photographs and slit-lamp analysis, we assessed cataract formation by light microscopy and inspection following lens extraction. We analyzed the lens in vitro rather than in vivo; nevertheless, we speculate that high OSI index may be associated with lenticular opacity.

Our study has some limitations. First, it would be better if we had additional study groups such as DM-only and steroid-only groups. Second, the effect of estrogen replacement was not investigated. Lastly, photographic analysis of the lens could be added for detailed cataract grading. Further, the model used could be referred to as oophorectomized rats instead of menopausal rats.

In conclusion, the outcomes of this study suggest that estrogen is not a protective factor against lenticular oxidative stress. In addition, methylprednisolone does not provide a protective effect against oxidative stress in crystalline lenses. The OSI was the highest in the menopause-diabetes model.

\section{REFERENCES}

1. Prokofyeva E, Wegener A, Zrenner E. Cataract prevalence and prevention in Europe: a literature review. Acta Ophthalmol. 2013;91(5):395-405.

2. Obrosova IG, Chung SS, Kador PF. Diabetic cataracts: mechanisms and management. Diabetes Metab Res Rev. 2010;26(3):172-80.

3. Robman L, Taylor H. External factors in the development of cataract. Eye (Lond). 2005; 19(10):1074-82.

4. Wang JJ, Rochtchina E, Tan AG, Cumming RG, Leeder SR, Mitchell P. Use of inhaled and oral corticosteroids and the long-term risk of cataract. Ophthalmology. 2009;116(4): 652-7.

5. Zetterberg M, Celojevic D. Gender and cataract-the role of estrogen. Curr Eye Res. 2014;40(2):176-90

6. Hutchinson CV, Walker JA, Davidson C. Oestrogen, ocular function and low-level vision: a review. J Endocrinol. 2014;223(2):R9-18.

7. Beebe DC, Holekamp NM, Shui YB. Oxidative damage and the prevention of age-related cataracts. Ophthalmic Res. 2010;44(3):155-65.

8. Berthoud VM, Beyer EC. Oxidative stress, lens gap junctions, and cataracts. Antioxid Redox Signal. 2009;11(2):339-53.

9. Chung SS, Ho EC, Lam KS, Chung SK. Contribution of Polyol Pathway to Diabetes-Induced Oxidative Stress. J Am Soc Nephrol. 2003;14(8 Suppl 3):S233-6.

10. Erel O. A new automated colorimetric method for measuring total oxidant status. Clin Biochem. 2005;38(12):1103-11.

11. Erel $\mathrm{O}$. A novel automated method to measure total antioxidant response against potent free radical reactions. Clin Biochem. 2004;37(2):112-9.

12. Lowry OH, Rosenbrough NJ, Far AL, Randall RJ. Protein measurement with folin-phenol reagent. J Biol Chem. 1951;193(1):265-75. 
13. Kosecik M, Erel O, Sevinc E, Selek S. Increased oxidative stress in children exposed to passive smoking. Int J Cardiol. 2005;100(1):61-4.

14. Vina J, Gambini J, Lopez-Grueso R, Abdelaziz KM, Jove M, Borras C. Females live longer than males: role of oxidative stress. Curr Pharm Des. 2011;17(36):3959-65.

15. Wagner H, Fink BA, Zadnik K. Sex- and gender-based differences in healthy and diseased eyes. Optometry. 2008;79(11):636-52.

16. Younan C, Mitchell P, Cumming RG, Panchapakesan J, Rochtchina E, Hales AM. Hormone replacement therapy, reproductive factors, and the incidence of cataract and cataract surgery: the Blue Mountains Eye Study. Am J Epidemiol. 2002;155(11):997-1006.

17. Wang JJ, Rochtchina E, Tan AG, Cumming RG, Leeder SR, Mitchell P. Use of inhaled and oral corticosteroids and the long-term risk of cataract. Ophthalmology. 2009; 116(4):652-7.

18. Dickerson JE Jr, Dotzel E, Clark AF. Steroid-induced cataract: new perspective from in vitro and lens culture studies. Exp Eye Res. 1997:65(4):507-16.

19. Creighton MO, Sanwal M, Stewart-DeHaan PJ, Trevithick JR. Modeling cortical cataractogenesis. V. Steroid cataracts induced by solumedrol partially prevented by vitamin E in vitro. Exp Eye Res. 1983;37:65-76.

20. Subhas G, Gupta A, Bakston D, Silberberg Bm, Lobocki C, Andrus L, et al.Protective effect of methylprednisolone on warm ischemia-reperfusion injury in a cholestatic rat liver. Am J Surg. 2010;199(3):377-80; discussion 380-1.
21. Akarsu E, Buyukhatipoglu H, Aktaran S, Kurtul N. Effects of pulse methylprednisolone and oral methylprednisolone treatments on serum levels of oxidative stress markers in Graves' ophthalmopathy. Clin Endocrinol (Oxf). 2011;74(1):118-24. Comment in: Nat Rev Endocrinol. 2011;7(2):62. Comment in: Clin Endocrinol (Oxf). 2011;74(1):118-24.

22. Osmanağaoğlu MA, Kesim M, Yuluğ E, Menteşe A, Karahan CS. The Effect of high dose methylprednisolone on experimental ovarian torsion/reperfusion injury in rats. Geburtshilfe Frauenheilkd. 2012;72:70-4.

23. Seven A, Aslan M, Incir S, Altıntaş A. Evaluation of oxidative and nitrosative stress in relapsing remitting multiple sclerosis: effect of corticosteroid therapy. Folia Neuropathol. 2013;51:58-64.

24. Boyaci MG, Eser O, Kocogullari CU, Karavelioglu E, Tokyol C, Can Y. Neuroprotective effect of alpha-lipoic acid and methylprednisolone on the spinal cord ischemia/reperfusion injury in rabbits. Br J Neurosurg. 2014 [ahead of print].

25. Chung SS, Ho EC, Lam KS, Chung SK. Contribution of Polyol Pathway to Diabetes-Induced Oxidative Stress. J Am Soc Nephrol. 2003;14(8 Suppl 3):S233-6.

26. Kyselova Z, Stefek M, Bauer V. Pharmacological prevention of diabetic cataract. J Diabetes Complications. 2004;18(2):129-40.

27. Oates PJ, Mylari BL. Aldose reductase inhibitors: Therapeutic implications for diabetic complications. Expert Opin Investig Drugs. 1999;8(12):2095-119.

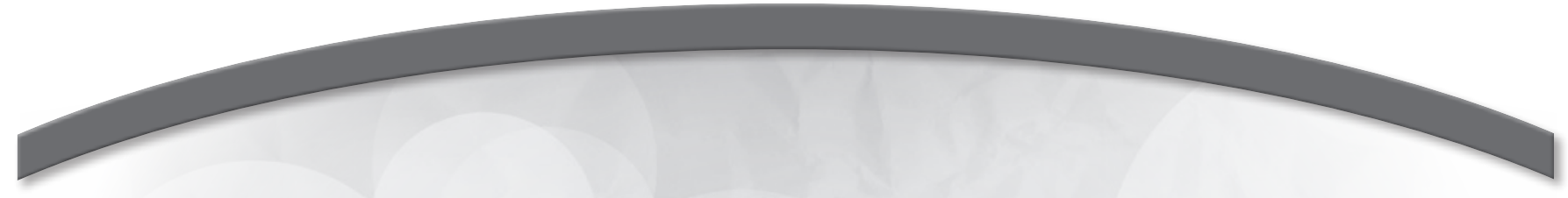

\title{
40- Simpósio Internacional \\ Moacyr Álvaro - SIMAsp
}

\author{
16 a 18 de fevereiro 2017 \\ Macksoud Plaza hotel \\ São Paulo - SP
}

Informações:

Tel.: (11) 5084-4246 / 5081-7028 